\title{
Functional Bodies in Functional Communities: What Tools are Needed to Measure Success?
}

\author{
Costley AW*
}

Department of Health \& Human Performance, USA

ISSN: 2578-0093

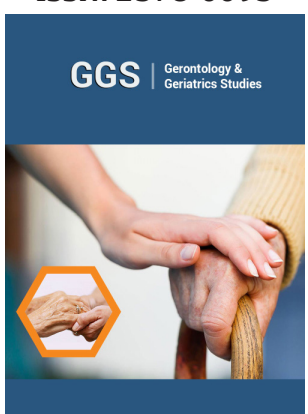

*Corresponding author: Costley AW, Department of Health \& Human Performance, USA

Submission: 僵 December 14, 2019

Published: 沮January 24, 2020

Volume 5 - Issue 4

How to cite this article: Costley AW. Functional Bodies in Functional Communities: What Tools are Needed to Measure Success?. Gerontol \& Geriatric stud.5(4). GGS.000618.2020.

DOI: $10.31031 /$ GGS.2020.05.000618

Copyright@ Costley AW, This article is distributed under the terms of the Creative Commons Attribution 4.0 International License, which permits unrestricted use and redistribution provided that the original author and source are credited.

\section{Abstract}

While "function" is often measured in terms of individual ability, a closer look at the history of wellestablished assessment tools and future directions in assessment show us that a focus on intrinsic factors is not enough. In a number of fields, the theory of "congruence" provides an important model to see that "fit" (or function) is always the product of a dynamic relationship between individual ability and environmental demands. But, as we embrace movements to promote "successful" and "active" aging through the transformation of communities and cities, more work is needed to measure how a range of extrinsic factors (cultural, social, economic, and physical) impact the expression of disability and actually support or improve function.

\section{Mini Review}

The assessment of functional ability is an essential practice of geriatric medicine and data on rates of function and disability are key indicators in gerontology and public health [1]. But, the relationship between health and function is often problematic and hard to measure. In 2006, the Population Council in the U.S. suggested that "while adding more years to life is often a goal for many, a more "fundamental question" is whether the "extra" years are spent in "good health or bad health," and subject to the most disagreement has been [our ability to measure] trends in abilities [specifically] to perform personal-care activities [2]. While dependency seems inevitable, the extent and degree, as well as contributing factors are harder to measure. The standard measure for the performance activities of daily living (ADLs) come from Katz (1963) who identified seven "fundamental" human tasks that include: eating, dressing, self-grooming, walking, getting in and out of bed, bathing, and using the toilet.

To this day, the Katz Index remains the standard for assessing general "functional disability" for older adults living in the community, even though it was originally designed to assess the rehabilitation process of hospitalized patients specifically with "fractures of the hip" [3]. While the intended and actual uses of this tool have diverged, measurement of "daily activity" has developed other problems as many tools since then have become more "simplified and dichotomous" in the response and scoring scales [4]. While Katz originally allowed for some types of "assistance" in his definition of "independence," this allowance has routinely been lost in translation over time where ratings of "dependency" on versions of the Index today now eliminate much of the original variability. This shift also seems to be present in measures of disability at the population level. In the U.S. National Long-Term Care Survey, for example, the criteria for "disabled" includes "any type of assistance, human or mechanical, for any ADL or for any IADL, lasting for "a minimum of 90 days," thus potentially inflating rates [5]. Lawton and Brody (1969) provided the now standard measure for Instrumental Activities of Daily Living (IADLs), including: using the telephone, shopping, preparing a meal, cleaning house, doing laundry, using transportation, managing medications, and managing finances.

These are shown to require a higher degree of "coordination, planning, and decisionmaking" if done independently [6]. But subsequent socio-cultural research has established that among older adults, rates of independence with IADLs (compared to ADLs) show more variability due to a variety of extrinsic factors: social, cultural, economic, and geographic [7]. In a cross-cultural study on ADLs and IADLs among English, West Indian, Asian, and Danish individuals (in England and Denmark), showed that "nearly all [ADLs] were performed by everybody, while none of the [IADLs] were performed by everybody" due to "cultural 
differences in washing habits and types of clothing" and "actual differences in health and differences in gender roles" [8].

In 2009, the National Research Council and the National Academy of Sciences called for improvements in the measurement of late-life disability in population surveys "beyond ADLs and IADLs" due to "substantial differences " in prevalence rates due to a diversity of "conceptual definitions," wording of questions in surveys, sampling, and methods of data collection. Also, while IADLs have typically been described as "concerned with a person's ability to cope with his or her environment," experts noted that a focus on the body, has neglected a focus on social context with few measures to assess the effect of the home on individuals. Applying a more dynamic and contextual view would encourage us to see that disability is always "experienced" within a social, environmental, and cultural context [9]. In social work, occupational therapy, and gerontological practice, we come closer to defining this relationship through the "person-environment congruence" or PE-fit model, where fit (or function) is the outcome of an appropriate balance between individual competence (or ability) and environmental press (or demands.

In research practice, however, achieving congruence has often been studied in a limited number of spaces (e.g. home, care unit, or workplace), with less study of interactions at the communitylevel, across time and changes in ability [10]. A number of different initiatives, local and global are now documenting the importance of our physical and social environments for aging well. In "lifespan" communities, a focus on the neighborhood-level identifies essential features to support activity, mobility, and inter-generational interaction for continuity in home and aging-in-place [11]. The WHO Global Age-Friendly Cities movement started in 2006, was adopted by 33 cities in 22 countries by 2014 as a practical guide to promote the material and social conditions needed to support "active ageing" and social engagement in older adults. The Checklist of "essential" features of age-friendly cities, is an ambitious list of 84 items across 8 domains that span municipal priorities ranging from the condition of public spaces to the cost of public transportation to the construction of housing and access to public events [12]. But more research is still needed on their impact, effectiveness, and measurable outcomes. These require more tools that are yet to be developed. As Golant (2014) observed, the benefits that seem obvious still need to be measured and proven in several important ways including:

1) whether these communities have the resources and opportunities to meet the needs of aging individuals and populations over time

2) how well these initiatives really "perform" to provide benefits to residents

3) how well they have led to improvements in the "physical or psychological well-being of older people and their greater ability to pursue their activities" [13].
The inability to "perform" ADLs and IADLs is actually a dynamic outcome resulting, in part, from a complex relationship between the meaning of adequate "ability" and the demands of out multiple environments shaped by multiple forces (social, historical, economic, and cultural). Developing the "tools" that we need to explore this outcome, might begin with rethinking out ideas of maintaining "independence" at all levels, which some have argued is a uniquely culture-bound concept [14]. A next step involves rethinking the reality and necessity of inter-dependence where high "function" might be better seen as the ability to maintain and manage the resources and "human capital" in our changing social networks. Finally, a more rigorous assessment of our "fit" within our social and physical communities can better identify that what really works for successful and active aging, in multiple settings and locations as ability and needs change over time.

\section{References}

1. Mortimer, James A (2003) Early detection and prevention: The future of geriatrics. The Beverly lecture on gerontology and geriatrics education, no. 18, Presented at the $29^{\text {th }}$ Annual Meeting of the Association for Gerontology in Higher Education. St Petersburg, Russia.

2. Population Council (2006) Trends in later life.

3. Katz S, Ford AB, Moskowitz RW, Jackson BA, Jaffe MW (1963) Studies of illness in the aged: The index of ADL: A standardized measure of biological and psychosocial function. JAMA 185(12): 914-919.

4. Bennet JA (1999) Activities of daily living: old fashioned or still useful? Journal of Gerontological Nursing 25(5): 22-29.

5. (NLTCS) (1999) National long-term care survey.

6. Lawton MP, Brody EM (1969) Assessment of older people: Selfmaintaining and instrumental activities of daily living. Gerontologist 9(3): 179-186.

7. Diehl M (1998) Everyday competence in later life: Current status and future directions. Gerontologist 38(4): 422-433.

8. Avlund K, Luck M, Tinsley R (1996) Cultural differences in functional ability among elderly people in Birmingham, England and Glostrup, Denmark. Journal of Cross-Cultural Gerontology 11(1): 1-16.

9. National Research Council (2009) Improving the measurement of latelife disability in population surveys: beyond ADLS and IADLS: summary of a workshop. The National Academy of Sciences Engineering Medicine.

10. Iwarsson S (2005) A long-term perspective on person-environment fit and ADL dependence among older Swedish adults." The Gerontologist 45(3): 327-336.

11. Stafford PB (2009) Design guidelines for a lifespan community. Center on aging and community, Indiana institute on disability and community. Bloomington, India.

12. World Health Organization (2007) Global age-friendly cities: A guide. World Health Organization Press, Geneva, Switzerland.

13. Golant S (2014) Age-friendly communities? Are we expecting too much? IRPP Insight 5: 1-20.

14. Portacolone E (2011) The myth of independence for older Americans living alone in the bay area of san Francisco: a critical reflection. Aging \& Society 31(5): 803-828. 